\title{
VARIATION IN THE ORIGIN OF SUPERIOR THYROID ARTERY
}

\author{
Gursharan Singh Dhindsa ${ }^{1}$, Shubhpreet Sodhi ${ }^{2}$
}

\section{HOW TO CITE THIS ARTICLE:}

Gursharan Singh Dhindsa ${ }^{1}$, Shubhpreet Sodhi. "Variation in the Origin of Superior Thyroid Artery". Journal of Evolution of Medical and Dental Sciences 2014; Vol. 3, Issue 22, June 02; Page: 5969-5972,

DOI: $10.14260 /$ jemds/2014/2691

\begin{abstract}
The variations in the distribution pattern of superior thyroid artery are of great importance for head and neck surgeons because of its vital relationship to the external laryngeal nerve. In this case an unusual unilateral variation in the arterial supply of thyroid gland was found during routine dissection of an elderly male cadaver in the Department of Anatomy, GGS Medical College, Faridkot, Punjab. The left superior thyroid artery took origin from the anterior aspect of left common carotid artery and it exhibited a usual relationship with the left external laryngeal nerve. The inferior thyroid arteries did not show any unusual distribution. Knowledge of such arterial variations related to the thyroid gland is immensely helpful for surgeons in order to put ligature on anomalous artery and to avoid damage to vital structures in this area. It is also helpful to the radiologists in interpreting the angiograms.
\end{abstract}

KEYWORDS: Superior thyroid artery, External carotid artery, Common carotid artery, Thyroid gland.

INTRODUCTION: The Superior Thyroid Artery (STA) is the main source of arterial blood to the thyroid gland, upper part of the larynx and neck region. It is a branch of external carotid artery (ECA) and arises from its anterior surface, just below the level of greater cornu of the hyoid bone. It runs downwards from its origin and gives a branch i.e. superior laryngeal artery (SLA) which pierces the thyrohyoid membrane along with the internal laryngeal nerve. It also gives an infrahyoid branch, a branch to the sternocleidomastoid muscle and a crico-thyroid branch. ${ }^{1}$

The relationship of the superior thyroid artery to the external laryngeal nerve is important to the surgeon during thyroid surgery. The artery and nerve are close to each other higher up but diverge near the gland. Thus in order to avoid injury to the external laryngeal nerve, the superior thyroid artery is ligated as near to the gland as possible. The STA is frequently used as a recipient vessel for microvascular free tissue transfer in head and neck surgery, for selective embolization of thyroid and head and neck tumors, and as a landmark for identifying the external laryngeal nerve in thyroid surgery. ${ }^{2}$

Surgical procedures involving the thyroid gland require a thorough knowledge not only of the normal gross anatomy of the structures within the region but also of the anatomical variations of the structures located within it. Thyroid surgery being a major surgery and quite often performed, a thorough knowledge of variations in arterial supply is very essential for surgeons to prevent alarming number of table deaths in patients with thyroid disease due to excessive and uncontrollable bleeding. It is also of help to the radiologists and physicians for proper physical examination and treatment of the patient and to the anatomists for learning the variant patterns.

CASE REPORT: During routine dissection of head and neck of an elderly male cadaver, for undergraduate students in the Department of Anatomy, GGS Medical College, Faridkot, we observed an anomalous origin of the left superior thyroid artery. For studying in detail, the sternocleidomastoid muscle was displaced laterally. The infrahyoid group of muscles were identified 
and reflected. After reflecting the sternohyoid and sternothyroid muscles the thyroid gland was exposed. The fascia was removed from the lobes of the thyroid gland. Normally, the superior thyroid artery is the first branch to arise from the external carotid artery, but in this case it was seen that the superior thyroid artery on the left side was arising from the common carotid artery, $14 \mathrm{~mm}$ before the common carotid artery had bifurcated into external carotid artery and internal carotid artery (Fig. 1,2). The length of main trunk of superior thyroid artery was measured from its origin to the apex of lateral lobe of the thyroid gland, which was $25.6 \mathrm{~mm}$. It was further observed that the left superior thyroid artery exhibited a usual relationship with the external laryngeal nerve. On the right side, the STA was arising from the External Carotid Artery and no other variation was seen. The Common Carotid Artery, except the STA on the left side, gave no other branches on either side.

DISCUSSION: Thyroid gland is the largest endocrine gland in the body and plays an important role in the maintenance of the basal metabolic rate and is a highly vascular endocrine gland. Generally, the common carotid artery does not give any branches except external and internal carotid arteries. ${ }^{3}$ Superior thyroid artery commonly arises from the external carotid artery. Faller and Sharrer ${ }^{4}$ reported that the superior thyroid artery may arise from the common carotid artery in 18\% of cadavers, from external carotid artery in $36 \%$ of cadavers or from the point of division of common carotid artery in $36 \%$ of cases. Chandralekha and Cooper ${ }^{5}$ studied the patterns of origin of superior thyroid arteries in 40 south Indian cadavers and it was observed that in $30 \%$ cases the superior thyroid artery arose from common carotid. Smith and Benton ${ }^{6}$ had reported the origin of superior thyroid artery from the uppermost part of the common carotid artery in 5\% of Swiss and 45\% of American cadavers. In their study, Rimi et al $^{7}$ observed that STA most commonly originated from external carotid artery (male- 76.5\% both right and left, female- $91.3 \%$ right, $73.9 \%$ left), followed by bifurcation of common carotid artery (male-right $14.7 \%$, left $20.6 \%$, female- left $13 \%$, right $0 \%$ ) and from common carotid artery (male $-8.8 \%$ right, $2.9 \%$ left, female- $8.7 \%$ right, $13 \%$ left) at the level or above the level of upper border of thyroid cartilage. Sanjeev IK et al ${ }^{8}$ found that the superior thyroid artery was arising from the anteromedial surface of the external carotid artery as the first branch in $64.86 \%$ of the cases and in $35.14 \%$ of the cases, it was found to arise from the common carotid artery. Anitha $\mathrm{T}$ et $\mathrm{al}^{9}$ in their study of 50 cadavers found the origin of STA from common carotid in 20\% cases on right side and from $22 \%$ cases on left side, from common carotid bifurcation in $18 \%$ cases on right side. Chandrakala and colleagues ${ }^{10}$ concluded in their study that the superior thyroid artery arose either from the common carotid artery in $9.1 \%$ cases or from external carotid close to the bifurcation of common carotid artery in $18.2 \%$ cases.

CONCLUSION: Ever since the thyroid gland has been discovered, it has been studied extensively by the anatomists, physiologists, pathologists, physicians and surgeons. Thyroid arteries are of much importance in providing blood supply to the gland. In case of thyroidectomy ligation of all the thyroid arteries is highly essential to ensure proper hemostasis. Moreover the intimate relationship of external laryngeal nerve with superior thyroid artery and recurrent laryngeal nerve with inferior thyroid artery should be kept in mind while ligating the thyroid vessels. From the above discussion, it is evident that there is possibility of a wide range of variations in the superior thyroid artery. Thus the knowledge of these variations could help to avoid serious implications during radiological examination, thyroid surgeries, tracheostomy, surgeries of larynx and microvascular surgeries. 


\section{CASE REPORT}

\section{REFERENCES:}

1. Standring S, Ellis H, Healy JC, Johnson D, William A, Collins P. From Gray's Anatomy: the anatomical basis of clinical practice. 39th Ed. London: Elsevier, Churchill Livingstone 2005, pp.543-547.

2. Vazquez T, Cobiella R, Maranillo E, Valderrama FJ, McHanwell S, Parkin I, Sanudo JR. Anatomical variations of the superior thyroid and superior laryngeal arteries. Head Neck 2009; 31: 107885.

3. Datta, AK. Essentials of human anatomy. $2^{\text {nd }}$ Ed. Calcutta, Current Books International 1994; 127-132.

4. Faller A, Sharrer O. Uber die Variabilitat des arteria thyroidea. Acta Anat.1947; 4: 117-119.

5. Chandralekha G, Cooper MM. Origin of superior thyroid artery. J Anat Soc India 1977; 26: 35.

6. Smith SD, Benton RS. A rare origin of Superior thyroid artery. Acta Anat.1978; 101: 91-93.

7. Rimi KR, Ara S, Hossain M, Shefyetullah KM, Naushaba H, Bose BK. Postmortem Study of Thyroid Arteries in Bangladeshi People. Bangladesh Journal of Anatomy 2009; 7: 26-33.

8. Sanjeev IK, Anita H, Ashwini M, Mahesh U, Rairam GB. Branching Pattern Of External Carotid Artery In Human Cadavers. Journal of Clinical and Diagnostic Research 2010; 4: 3128-3133.

9. Anita T, Dombe D, Asha K, Kalbande S. Clinically relevant variations of superior thyroid artery: an anatomic guide for neck surgeries. Int J Pharm Biomed Sci 2011; 2(2): 51 -54.

10. Chandrakala SP, Swapnali, Mavishettar GF. Variations in the origin and branching patterns of superior thyroid artery. Anatomica Karnataka 2011; 5(3): 20-24.

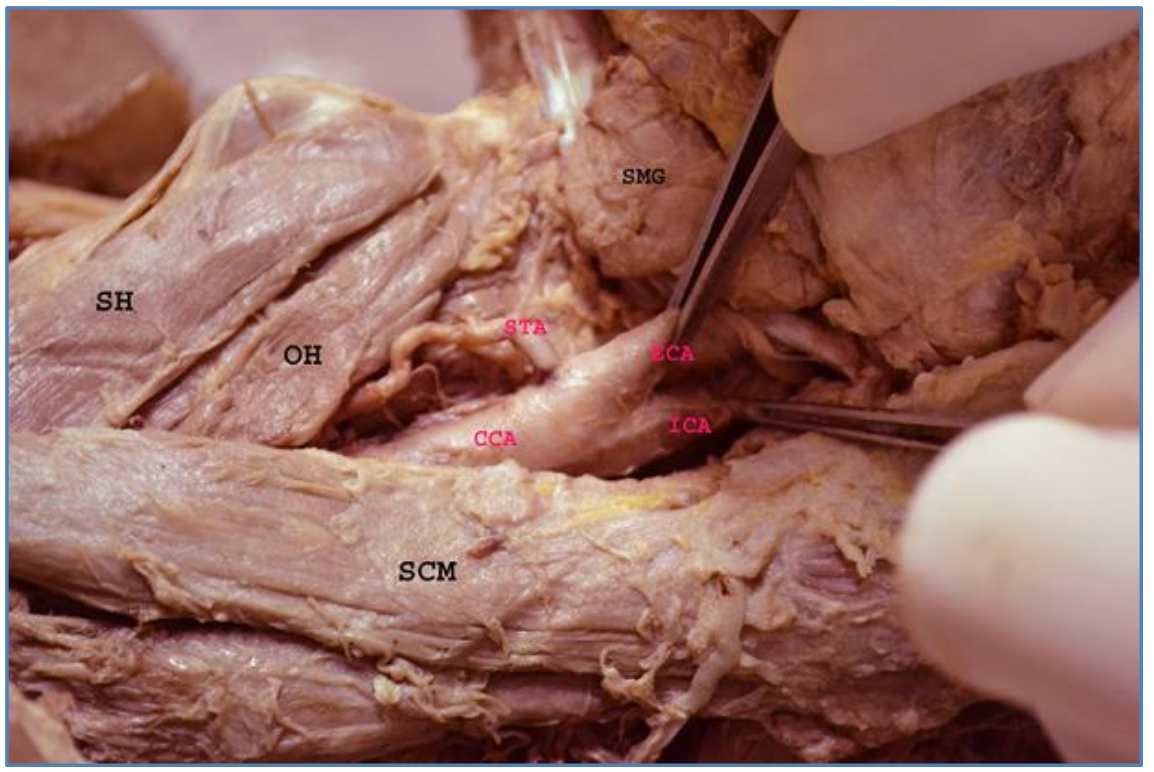

Fig. 1: Showing variation in the origin of the left superior thyroid artery

CCA- Common Carotid Artery

ECA- External Carotid Artery

ICA- Internal Carotid Artery

STA- Superior Thyroid Artery
SCM- Sternocleidomastoid Muscle

SH- Sternohyoid

$\mathrm{OH}$ - Omohyoid

SMG- Submandibular Gland 


\section{CASE REPORT}

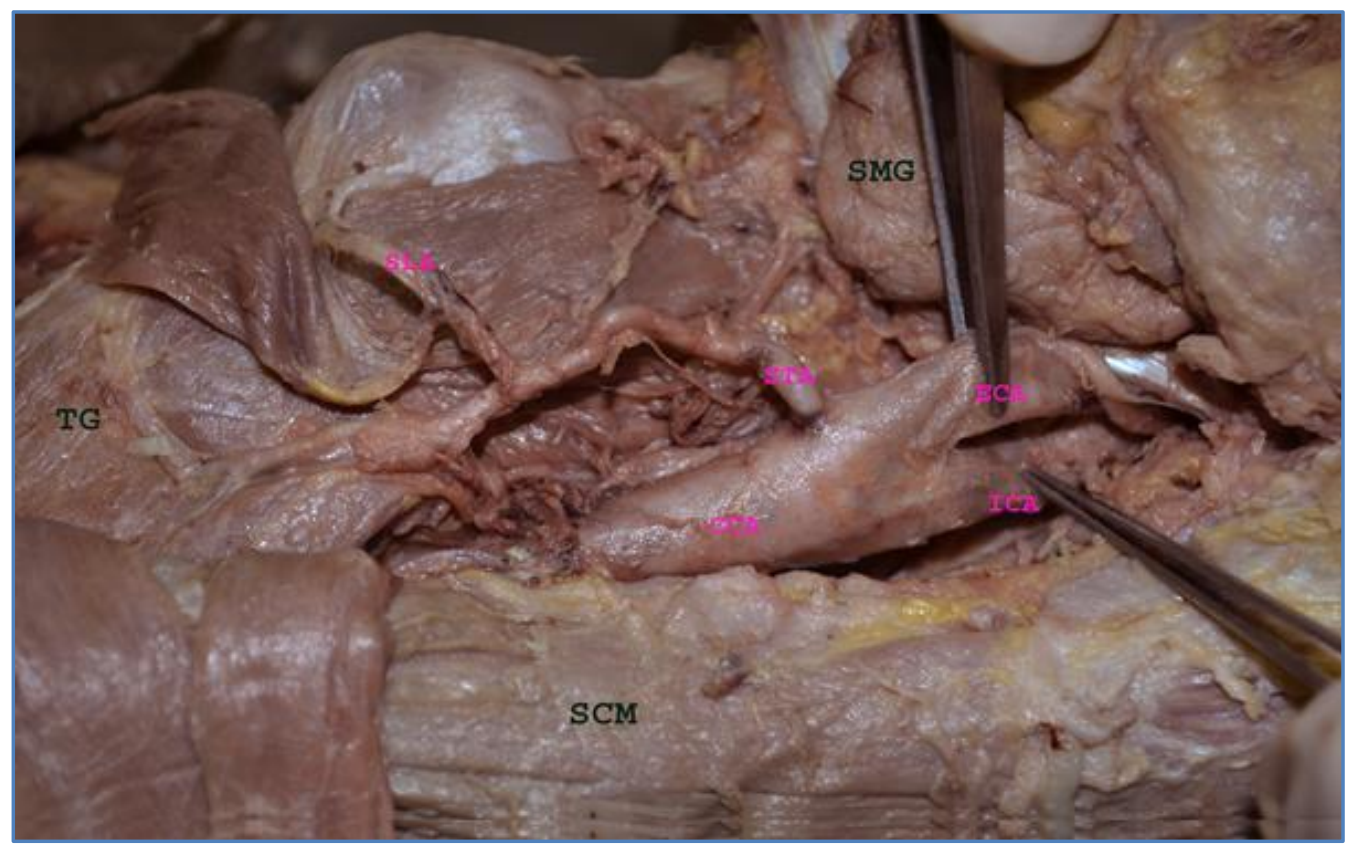

Fig. 2: Showing the course of the left Superior thyroid artery after removing the infrahyoid muscles

CCA- Common Carotid Artery

ECA- External Carotid Artery

ICA- Internal Carotid Artery

STA-Superior Thyroid Artery
SLA-Superior Laryngeal Artery

SCM- Sternocleidomastoid Muscle

TG- Thyroid Gland

SMG- Submandibular Gland

\section{AUTHORS:}

1. Gursharan Singh Dhindsa

2. Shubhpreet Sodhi

\section{PARTICULARS OF CONTRIBUTORS:}

1. Assistant Professor, Department of Anatomy, Guru Gobind Singh Medical College, Faridkot, Punjab.

2. Demonstrator, Department of Anatomy, Guru Gobind Singh Medical College, Faridkot, Punjab.

\section{NAME ADDRESS EMAIL ID OF THE} CORRESPONDING AUTHOR:

Dr. Gursharan Singh Dhindsa, Assistant Professor,

Department of Anatomy,

Guru Gobind Singh Medical College,

Sadiq Road, Faridkot, Punjab.

Email: gursharan91@rediffmail.com

Date of Submission: 09/05/2014.

Date of Peer Review: 10/05/2014.

Date of Acceptance: 21/05/2014.

Date of Publishing: 28/05/2014. 